\title{
Profiles of Elementary Teachers' Use of Mathematics Curriculum Materials and the Influence of Teacher Expertise
}

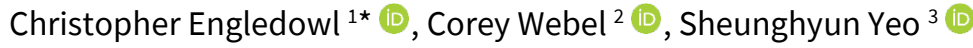

\author{
${ }^{1}$ New Mexico State University, NM, USA \\ ${ }^{2}$ University of Missouri, MO, USA \\ ${ }^{3}$ University of Alabama, AL, USA \\ *Corresponding Author: chriseng@nmsu.edu
}

Citation: Engledowl, C., Webel, C., \& Yeo, S. (2021). Profiles of Elementary Teachers' Use of Mathematics Curriculum Materials and the Influence of Teacher Expertise. International Electronic Journal of Mathematics Education, 16(2), em0626. https://doi.org/10.29333/iejme/9702

ARTICLE INFO

Received: 3 Oct. 2020

Accepted: 1 Dec. 2020

\section{ABSTRACT}

The National Council of Teachers of Mathematics has consistently emphasized the importance of curricular coherence in mathematics education. However, the predominance of the Internet has led to a lack of consistency in the use and quality of curricular materials. We drew on teachers' self-report of their use of curriculum materials and conducted a Latent Class Analysis to examine patterns in 56 elementary teachers' selection, use, and perceptions of materials for teaching mathematics, including the role that teacher expertise may play in these patterns. Findings indicated that the most salient difference between classes was at least one digital resource reported-the Blended class-and no digital resources reported-the Non-Digital class. Teacher expertise was not a significant covariate. Future research should examine the role of policies on teachers' curricular decisions. Implications include how specialist programs may support positive patterns of curriculum selection and use.

Keywords: curriculum selection, elementary mathematics, teacher expertise, latent class analysis

\section{INTRODUCTION}

The National Council of Teachers of Mathematics (NCTM) has consistently emphasized the importance of curricular coherence in mathematics education, explaining that "a coherent curriculum effectively organizes and integrates important mathematical ideas so that students can see how the ideas build on, or connect with, other ideas" (2000, p. 15). However, reports showing that teachers of mathematics are increasingly searching the Internet to find instructional materials to use with students (Davis, Choppin, Roth McDuffie, \& Drake, 2013) have led to concerns about curricular coherence and calls for developing expertise among teachers for filtering and adapting materials found on the Internet (Webel, Krupa, \& McManus, 2015).

However, finding, recognizing, and using potentially effective materials requires knowledge about the sequencing and delivery of mathematical content as well as the ability to navigate whatever constraints and demands are placed on the teacher as a result of their position and context. Such expertise may be more prevalent among teachers who have specialized training in mathematics education, such as those who complete programs leading to certification as Elementary Mathematics Specialists (EMSs) (Fennell, 2011). For example, EMSs may be more skeptical of resources in general, may be more likely to modify or reject materials that do not fit a more refined vision for mathematics instruction, or may feel more confident about selecting and using curricular resources that are outside the recommendations of their school or district.

In this paper, we share data about the curricular practices reported by participants in a larger project that focuses on the impact of EMSs who work as classroom teachers. Using a detailed survey, we first explored the extent to which our participants, regardless of EMS classification, used digital or text-based resources, the extent to which they modified these, their satisfaction with their curriculum options, and also whether the resources they used were mandated or suggested by their administration. Using Latent Class Analysis, we created profiles to distinguish groups of teachers who engaged in different sets of practices regarding their curricular decision making. Next, we examined whether there were differences in the selection, use, and perceptions of curriculum between the EMSs and comparison teachers working at the same or nearby schools.

\section{RESEARCH QUESTIONS}

1. How do elementary teachers report their use of, and satisfaction with, digital and textbook resources for teaching mathematics? (RQ1) 
2. What are the characteristics of profiles that distinguish between patterns in how elementary teachers select, use, and rate mathematics curriculum resources? (RQ2)

3. In what ways do EMS-certified teachers differ from their peers in terms of their curriculum resource selection and use? (RQ3)

\section{THEORETICAL PERSPECTIVE AND LITERATURE REVIEW}

In her review of research on how teachers use curriculum materials, Remillard (2005) outlined four conceptualizations of the teacher-curriculum relationship: 1) teacher as following or subverting the text, 2) teacher as drawing on the text, 3) teacher as interpreting the text, and 4) teacher as participating with the text. In this paper, we adopt the perspective that teachers are drawing on texts to create learning experiences for learners. This perspective foregrounds the agency of the teacher and emphasizes the teacher's decision making around selecting which resources to use and how. It also positions curriculum resources as just one influence among many on classroom practice.

\section{Teachers' Use of Curriculum}

Curriculum resources have historically been seen as one of the primary drivers of mathematics teaching reform efforts (Lloyd, Cai, \& Tarr, 2017). However, there is a large body of research documenting the ways that teachers modify and adapt their materials (Heck, Chval, Weiss \& Ziebarth, 2012; Remillard, 2005; Remillard, Herbel-Eisenmann, \& Lloyd, 2009), and recently there has been a shift toward viewing curriculum materials as resources that teachers can use to achieve particular instructional goals (Roth McDuffie \& Mather, 2009).

Under this perspective, teachers have agency to make decisions about what resources to use and how. They make these curricular decisions for a variety of reasons, including their goals for specific lessons (Drake \& Sherin, 2009), their understanding of the mathematical ideas in the textbooks (Charalambous et al., 2012; Hill \& Charalambous, 2012; Stein \& Kaufman, 2010), and their beliefs about mathematics, students, and teaching (Arbaugh et al., 2006; Lloyd \& Wilson, 1998; Manouchehri, 1998; Sleep \& Eskelson, 2012).

For example, research has revealed a complex relationship between knowledge and curriculum use (Hill et al., 2008; Hill \& Charalambous, 2012; Stein \& Kaufman, 2010). In general, stronger content knowledge is related to higher quality instruction (in terms of richness of the mathematical language employed during instruction, the explanations offered, the avoidance of errors, etc.), but the quality of the curriculum also plays a role. For teachers with strong content knowledge, more ambitious textbooks supported their use of quality instruction, but for teachers with weaker knowledge, the same textbooks were more challenging to use and sometimes resulted in lower quality instruction (Hill et al., 2008).

Teachers' beliefs also influence their curricular decisions. For example, Arbaugh and colleagues (2006) found that teachers who believed that all students can do high quality mathematics were more likely to implement a standards-based textbook in ways that were consistent with its authors' intent. Sleep and Eskelson's case study of two teachers (2012) showed that a combination of mathematical knowledge for teaching (MKT) and specific orientations toward mathematics and goals for student learning were necessary to use teaching practices like using multiple representations and eliciting multiple solution methods when using high quality curriculum materials

In addition to individual resources like knowledge and beliefs, school and district policy also can influence curricular enactment, both directly-e.g., requiring teachers to follow a pacing guide or forbidding certain resources-and indirectly-e.g., supporting the development of teacher's capacity to enact a curriculum. Even in the latter case, we still argue for the agency of the teacher, who is able to make modifications within the requirements of the district and in some cases, may engage in "creative insubordination" (Guitérrez, 2016) in order to resist or subvert the policy requirements around the use of textbooks. For example, Webel and colleagues (2017) described how the teacher Leah would sometimes deviate from her textbook by changing the sequence of activities or omitting certain instructions (such as relying on key words), even though she perceived her district as expecting fidelity in use of the curriculum resource. She conveyed a sense of covertness to these deviations, "implying that such changes were in opposition to district policy and needed to be made in secret" (p. 207). This case shows that teachers do exercise agency underneath what may seem to be rigid set of curriculum policies.

Some research has found that curriculum-specific professional development is a significant factor in predicting effectiveness (Schoen, Cebulla, Finn, \& Fi, 2003), though other research has not found such effects (Tarr, Grouws, Chavez, \& Soria, 2013). In the context of state level reform in California, Cohen and Hill (2001) found that

the things that made a difference to changes in their practice were integral to instruction: curricular materials for teachers and students to use in class; assessments that enabled students to demonstrate their mathematical performance-and teachers to consider it-and instruction for teachers that was grounded in these curriculum materials and assessments. (p. 6)

There are further influences on curriculum use that fall outside of teachers' control, such as school and district policies. The Horizon 2018 study (Banilower et al., 2018) showed that $72 \%$ of elementary mathematics classes were reported to have districtrequired instructional materials. Moreover, $89 \%$ were reported to have a district-required commercially published textbook and $76 \%$ reported basing instruction on the district-required commercially published textbook at least once per week. Although teachers appear to not have much external influence on their instructional materials, Banilower et al. (2018) also reported that in their most recent mathematics lesson, teachers indicated supplementing their district-required textbook with "other sources" 
(69\%), modifying the textbook materials (61\%), and selecting only what was deemed most important and "skipping the rest" (49\%) (p. 144). They followed-up to find out why teachers skipped portions, supplemented, and modified their district-required textbook. They found that teachers skipped most often because they had other activities they thought would "work better" (80\%), because the material was not included in their pacing guide or standards (65\%), because there was not enough time (61\%), or because they perceived their students as already knowing the material or not needing the activity skipped in order to learn the material (67\%) (p. 145). The most common reason teachers reported supplementing was to give students additional practice (95\%), to support students at differing levels (94\%), or because they simply liked other activities better (80\%) (p. 146). With regard to modifying, the most frequent reasons reported were because there was not enough instructional time (52\%), the "activities were too easy conceptually" (52\%), and the "activities were too difficult conceptually" (50\%) (p. 147).

\section{Digital Curriculum Resources}

In the past decade, the increasing availability of digital curriculum resources (DCRs) has led to new research on how these are being used and how they are influencing mathematics instruction (e.g., Hoyles, Noss, Vahey \& Roschelle, 2013; Pepin et al., 2017; Roschelle et al., 2010). Studies also have identified the distinct features of DCRs compared to traditional hard copy texts. For example, Choppin and Borys (2017) analyzed eight digital programs and identified four such features: "afford transformative learning experiences; provide access to high-quality and freely available materials; facilitate customizability or individualization of content; and include embedded assessment systems that adapt programs to the needs of the learner" (p. 664). Students' learning experiences can be transformative through connecting to a more relevant context and deepening interactivity. The US Department of Education (2016) encouraged districts to use open resources and to share expertise with others in order to increase accessibility to high-quality mathematics as a means of addressing equity concerns. DCRs can be customized by providing different content to meet the needs of individual students. The assessment system of digital materials can provide instant feedback to students and report their performance to stakeholders (e.g., teachers, principals).

In the Horizon survey (Banilower et al., 2018), 28\% of elementary teachers reported being required to use mathematics "lessons or resources from websites that are free (e.g., Khan Academy, Illustrative Math)", 31\% reported being required to use "subscription based websites providing lessons/resources (e.g., BrainPOP, Discover Ed, Teachers Pay Teachers)", and 33\% reported being required to use "online units/courses students work through at own pace" for mathematics (p. 134). Percentages of teachers reporting actually using resources in each of these categories at least once a week were $37 \%, 54 \%$, and $36 \%$, respectively, while $76 \%$ reported using commercially published textbooks as the primary resource used to base instruction on. This suggests that many teachers are using DCRs from various sources and frequently utilizing them in addition to, but not as replacements for, traditional textbooks in their classrooms.

When teachers integrate DCRs into their mathematics lessons, they exercise agency by deciding what to use, how to use it, and how the various pieces of their curriculum will fit together. As Remillard (2016) describes, the teacher's role is much like that of a cartographer mapping new terrain. As the digital landscape changes-as new technological tools and resources are developed and others become obsolete-teachers' curricular decision-making also changes. Guided by state- and district-level standards and policies, teachers map out domains and paths for students to navigate the terrain more efficiently and effectively. Gueudet and Trouche (2009) describe the selection, planning, and enactment of resources as a process of documentational genesis and argue that "this documentation work is at the core of teachers' professional activity and professional development" (p. 199).

But the increase in the availability of online resources can create challenges. For example, Webel and colleagues (2015) found that a group of 29 fifth grade mathematics teachers failed to notice fundamental differences in the ways that different resources conveyed the same mathematical ideas, and instead attended to surface-level characteristics and whether students would find them enjoyable or be able to successfully complete them. The same study showed substantial variation among the group in terms of their use of online and print materials.

Other research shows that when incorporating DCRs, teachers tend to consider practical criteria such as ease of use and alignment with the other curricular programs (Choppin \& Borys, 2017). First, the ease-of-use concern has implications not only for children but also for teachers in implementing digital materials. Teachers might prefer a low-maintenance resource, such as a printable worksheet or quiz-type website, to a more complex virtual environment that requires additional learning or training prior to implementation. This means that even teachers who see promise in the use of DCRs might be frustrated with a lack of time for learning how to use the materials productively (Hanson \& Carlson, 2005). Second, teachers prefer DCRs designed for alignment with the curriculum. To meet these needs, many commercial DCRs (e.g., ST Math, see Yeo, 2018) emphasize their alignment with Common Core State Standards for Mathematics (NGACBP \& CCSSO, 2010), ostensibly to assure teachers that the resources will support, rather than interfere with, current teaching goals. On the other hand, if teachers implement explorative type tools such as computer algebra systems or dynamic geometry software, they have to spend more effort to make connections between the activity and curriculum (Kasten \& Sinclair, 2009).

To be sure, not all teachers are eager to learn new technology and adopt DCRs in their classroom, as documented by Drijver and colleagues (2013). Their study differentiated between an "early-adopter" group, which was open to and had experience with DCRs, and a large group of 'mid-adopting' teachers with much more limited experience. Drijver and colleagues showed that these less experienced teachers could develop technological knowledge and skills through teaching experiments with supports. Other barriers to the adoption and use of DCRs are related to characteristics such as nonlinear and opaque structures (Usiskin, 2013). The content of printed materials is typically easier to perceive holistically than digital materials. When teachers look for specific content, they can go to the chapter list and find the information they want. However, in DCRs, they might struggle to find content due to the multi-layered nature of the interface, requiring users to more fully explore the materials, perhaps requiring guidance from others. 
Table 1. Professional Background and Experience of Participating Teachers

\begin{tabular}{lcc}
\hline Characterizations of teachers & EMS (n=25) & Non-EMS (n=31) \\
\hline Gender (\%) & 100 & 93.5 \\
\hline Female & 92 & 74.2 \\
\hline Initial Certification (\%) & 4 & 16.1 \\
\hline Bachelor & 4 & 9.7 \\
\hline Post-baccalaureate & & \\
\hline Master & 48 & 4 \\
\hline Teaching Assignment (\%) & 4 & 3.5 \\
\hline Departmentalized & 24 & 3.2 \\
\hline Secondary mathematics certification (\%) & 72 & 9.1 \\
\hline Meanter degree & $11.5(7.0)$ & \\
\hline
\end{tabular}

\section{Elementary Mathematics Specialists and Curriculum Use}

The literature above indicates a complex relationship between teachers' beliefs, knowledge, and their use of curricular resources. One group of teachers who might be expected to stand apart in their use of curricular materials, including their decisions about DCRs, are those who have experienced an EMS program, designed to develop expertise in mathematics teaching at the elementary level. Such programs have been shown to impact beliefs and knowledge (Campbell \& Malkus, 2014; Swars et al., 2018), and graduates of such programs have gone on to serve as mathematics coaches, curriculum coordinators, intervention specialists, and classroom teachers (de Araujo, Webel, \& Reys, 2017), while also exhibiting 1) higher levels of MKT, 2) higher confidence in their own mathematics knowledge, and 3) lower rates of viewing mathematics as computation (Webel et al., 2018). However, we were unable to find research that explored specifically how EMSs select or use curricular resources. Compared to their peers, they might be expected to better recognize high quality materials, more regularly substitute these for low quality materials, or make adaptations to improve materials.

At the same time, we recognize that EMSs work in schools with expectations about curricular use. Some schools may limit the extent to which they can adapt resources, or may require adherence to a strict pacing guide or the use of a specific digital tool. And most teachers in the United States face some measure of accountability for what they teach; notably, although not exclusively, in the form of state tests. Pressure to cover the tested material may constrain the kinds of curricular decisions that teachers are, or feel, able to make. In other words, teachers work in roles that have boundaries. They are not free to do what they want; they can make choices, but these choices are not cost-free (Herbst, 2010).

\section{METHOD}

This study takes a quantitative survey design, employing the use of Latent Class Analysis to support development of profiles of teachers based on patterns in their responses to survey items. Across this section, where differences exist, they will be described in the context of each of the three research questions: teachers' reported use of, and satisfaction with, curriculum resources (RQ1), patterns of teachers' use of curriculum materials (RQ2), and the role of teacher expertise in teachers' use of curriculum materials (RQ3).

\section{Background and Participants}

This study draws on a larger three-year project which sought to investigate the impact of teachers' expertise and assignment in elementary mathematics classrooms. Teachers were recruited as participants who had completed a two-year EMS certification program. The EMS program consists of content and pedagogical knowledge and mathematics leadership roles in elementary schools, and was designed according to the Association of Mathematics Teacher Educator's (2013) standards for EMSs. The EMS participants $(n=47)$ were recruited from teachers who graduated from the EMS program in a Midwestern State and were currently teaching at the $3 \mathrm{rd}$, 4th, and 5th grade-level (ages 8-11). A comparison group of non-EMS teachers $(n=48)$ was also recruited from the same schools (or the same district, if there were no other teachers at the matching grade level at the school) and grade-level based on matching background characteristics such as the years of teaching experience and academic degree.

For the current study, we narrowed our focus to a subset of 25 EMS-certified teachers and 31 non-EMS teachers (total $n=56$ ) who responded to a mid-year survey about the use of curriculum resources in the second and third year of the project. Although we found the comparison group of teachers had similar backgrounds, the participating teachers have several distinct differences (Table 1). For example, the EMSs were assigned differently depending on school policies. Forty-eight percent of the EMS teachers taught mathematics to multiple classes or grade-levels over the school year (departmentalized). The average number of years of experience of EMS $(M=11.5)$ was also slightly higher than non-EMS teachers $(M=9.1)$. In addition, the EMSs showed stronger levels of mathematical knowledge for teaching, as measured by the Learning Mathematics for Teaching assessment (Hill, 2010), and also were less likely to report beliefs emphasizing computational skill as an important aspect of mathematics teaching and learning (Webel et al., 2018). 


\section{Data Sources}

Teachers' reported use of and satisfaction with curriculum resources (RQ1), and the overall patterns in teachers' use of curriculum resources (RQ2). In regard to the first and second research question, we drew mostly upon teachers' responses to an item on the survey that read:

In mathematics class, students often engage with different kinds of instructional materials, such as textbooks, websites, and/or apps. Please indicate the name(s) of the major textbooks/programs/websites used by the students in your class, and answer the following questions about each. You need not use all rows.

This item was modified from the 2012 national survey of mathematics and science teachers conducted by Horizon (Banilower et al., 2013; see items 40-45 of the Mathematics Teacher Questionnaire). In our survey, a table followed this stem in which teachers listed resources and then reported 1$)$ their level of satisfaction with the quality of each resource $(1=$ very unsatisfied, $2=$ not satisfied, $3=$ satisfied, 4 = very satisfied), 2 ) the extent to which they modified each resource $(1=$ never, $2=$ seldom, $3=$ sometimes, $4=$ most of the time), and 3) the approximate percentage of overall instructional time that students engaged with each resource (to sum to $100 \%$ across the list of resources). Use of these items allowed us some insight into the types of agency that teachers were exercising (Remillard, 2005). We used this item to extract the following 5 pieces of information in order to make sense of teachers' use of curriculum materials: 1) the number of text curriculum resources teachers reported using, 2) the number of digital curriculum resources teachers reported using, 3) the overall level of satisfaction teachers reported per resource, 4) the overall extent to which teachers reported modifying each resource, and 5) whether a single resource was reported being used by students at least $75 \%$ of instructional time. We hypothesized possible relationships between these categories; for example that teachers might modify resources more frequently when less satisfied with them, or they might use them less often. We then categorized the reported resources as either TEXT or DIGITAL. This allowed us to consider how teachers may have been making use of DCRs. A resource was categorized as TEXT if it was available in a non-digital format. On the other hand, a resource was categorized as DIGITAL if it was only available digitally. For instance, Eureka Math is available both digitally and non-digitally, and therefore was categorized as TEXT. However, Moby Max is only available digitally, and therefore was categorized as DIGITAL.

In order to transform the data into a format appropriate for the analysis method associated with RQ2 (Latent Class Analysis, described in the next section), we dichotomized each of these five data sources. Regarding the number of TEXT and DIGITAL curriculum resources, we re-coded the data to represent those with none of the resource, and those with at least one of the resource type ( 1 = none, 2 = at least one).

To investigate reported trends towards the use of multiple resources (as in Banilower et al., 2018), we also wanted to capture the amount of instruction that appeared to be driven by a single resource versus a blend of different materials within our sample. To do this, we created a variable (SINGLERES) to indicate whether a teacher reported that students used a single resource at least $75 \%$ of instructional time ( $1=$ one resource used at least $75 \%$ of the time, $2=$ no resource used at least $75 \%$ of the time). For instance, a teacher could have reported 2 text curriculum resources and 3 digital curriculum resources. If any one of those 5 resources was used at least $75 \%$ of the time by students, then this teacher would be given a SINGLERES value of 1 .

The satisfaction (SATISFY) and modification (MODIFY) variables were created to indicate an overall representation of how satisfied teachers were with their curricular options and choices and how much they modified the resources that they used. However, because different resources were being used for different proportions of time, we used a weighted mean for both SATISFY and MODIFY, based on those percentages of student use. For instance, suppose a teacher reported 4 resources with the following student use percentages and satisfaction ratings:

- Resource 1: SATISFY = 4 (very satisfied), $60 \%$ student use

- Resource 2: SATISFY = 2 (unsatisfied), $25 \%$ student use

- Resource 3: SATISFY = 3 (satisfied), $10 \%$ student use

- Resource 4: SATISFY = 4 (very satisfied), 5\% student use

In this example, a weighted mean SATISFY score would be generated as: $4^{\star} .60+2^{\star} .25+3^{*} .10+4^{\star} .05$. Therefore, the teacher would be given a score of 3.4 for the SATISFY variable. After weighted scores were generated for all teachers for both SATISFY and MODIFY, they were dichotomized to indicate teachers who were more or less satisfied in general with their curricular resources (1 $=$ SATISFY weighted score of 3 or more, $2=$ less than 3$)$ and who modified resources more or less frequently $(1=$ MODIFY weighted score of 3 or more, 2 = less than 3 ).

Differences in selection and use of curriculum between EMSs and their peers (RQ3). In addition to the items discussed above, to examine the third research question we drew on some other items in the teacher survey that were adapted from Horizon's survey (Banilower et. al., 2013) about the extent to which teachers perceived having control over their curricula. The main item stated: "How much control do you have over each of the following aspects of mathematics instruction in your class?" (Banilower et al., 2013, item 32, page 11 of the Mathematics Teacher Questionnaire in Appendix B). It was followed by several subitems in which teachers selected a value on a 5 -point scale $(1=$ no control, $3=$ moderate control, $5=$ strong control; values of 2 and 4 did not have descriptors) to indicate their perceived control. Specifically, we drew on responses to these sub-items because they were used by Banilower et al. (2013) in the creation of a composite score to measure curriculum control:

- Determining course goals and objectives

- Selecting textbooks/modules

- Selecting content, topics, and skills to be taught 


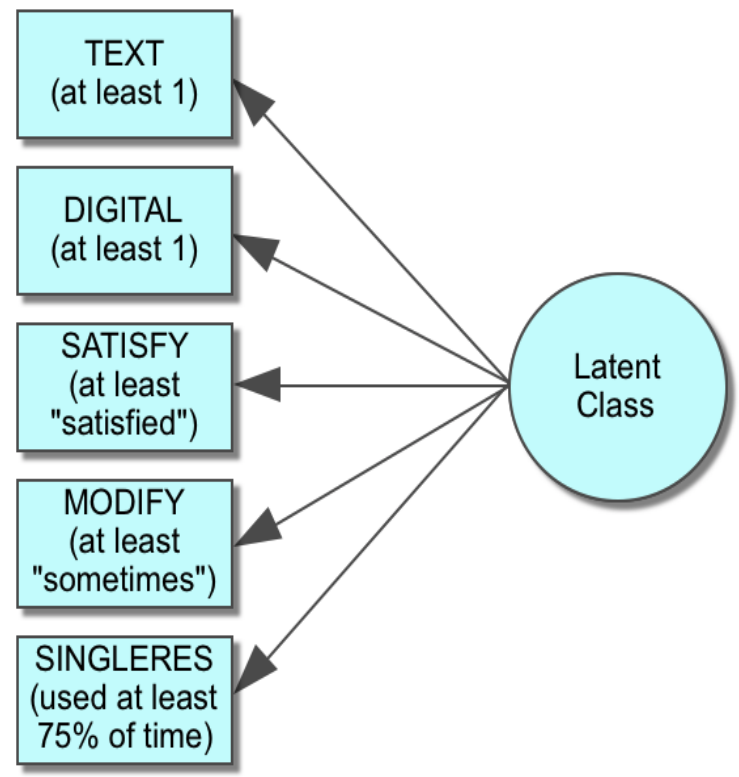

Figure 1. Latent Class Analysis model representation

We followed Banilower and colleagues' construction of the composite (see Weis \& Banilower, 2014, p. A-6 for details of the composite construction) and calculated an arithmetic mean from these items that collectively indicates teachers' reported level of curriculum control (CURRCONT).

To further examine RQ3, we used an item that asked teachers to indicate whether the instructional materials they reported having their students engage with were required, suggested, or neither required nor suggested, by their district or school administration. This allowed us to examine whether previous reports about how teachers use curriculum materials might be related to teacher expertise (e.g., Webel et al., 2017). We created a variable (REQUIRED) and coded whether teachers used at least one resource that was neither required nor suggested by their district $(1=$ all resources were required or suggested, $2=$ at least one resource neither required nor suggested). This served as an indication of the extent to which teachers in the sample were seeking, selecting, and using resources on their own initiative, which would represent a significant shift from the traditional relationship between teachers and curriculum materials.

\section{Data Analysis}

Analyzing teachers' reported use of and satisfaction with curriculum resources (RQ1). To address this first research question, we used basic descriptive statistics (frequency counts, measures of central tendency, and measures of spread) and visualization methods (dotplots, boxplots, histograms). Results from this analysis aid in contextualizing the second and third question because they provide a broader picture of the data used to investigate them. For instance, we provide a discussion of findings from descriptive analysis related to each of the variables used in the latent class analysis model used to examine both RQ2 and RQ3. This allows for an understanding of each variable before discussing patterns involved across them collectively.

Analyzing the overall patterns in teachers' use of curriculum resources (RQ2). In order to address this second research question, to identify groups of teachers who exhibited common patterns of curriculum use, we made use of the quantitative method Latent Class Analysis (LCA) using the R package poLCA (Linzer \& Lewis, 2011). LCA is commonly viewed as a special case of Cluster Analysis and a subset of Structural Equation Modeling. In LCA, cases (i.e., individuals) are grouped according to common patterns of response to a pre-determined set of categorical variables-in our case, dichotomous categorical variables. These groupings, called classes, are then described based on probabilities of responses within each class. In the context of this study, LCA allowed us to identify latent classes of patterns in teachers' curriculum use that would otherwise be difficult to detect.

We included the TEXT, DIGITAL, SATISFY, MODIFY, and SINGLERES variables in the LCA model (see Figure 1). These variables have been found to play important roles in teachers' curricular decision-making (e.g., Son \& Kim, 2015), and we therefore hypothesized that patterns would emerge accordingly. Moreover, initially, we had hypothesized that 1) the total number of resources a teacher reported and 2) teachers' reported curriculum control (CURRCONT) might aid meaningfully in distinguishing between classes. However, including these two variables in several successive models, pairing them with various groupings of the other 5 (including each separately), did not prove useful in explaining the differences between classes. That is, inclusion of these variables did not improve the model fit statistics, and they were also not clearly aligned with one class-teachers were observed to report in similar ways on these two variables regardless of which class they were in. Therefore, they were removed from the final model. To establish how many latent classes to extract, we began by extracting 2 classes and then extracted 3 classes. Due to the relatively small sample size-which was deemed appropriate for detecting a large effect (Dziak et al., 2014)-a model with 4 or more classes resulted in classes with too few teachers represented, thus, a 4-class model was not explored further. In particular with poLCA (Linzer \& Lewis, 2011), LCA models are estimated using the maximum likelihood estimation method, which may only find a local maximum of the log-likelihood function. Therefore, 100 iterations were conducted for each model to ensure the global maximum was determined. Afterward, we compared the model fit statistics for the 2-class and 3-class models, paying 
Table 2. Latent class analysis fit statistics for 2-class and 3-class models

\begin{tabular}{cccc}
\hline Number of classes & Maximum Log-likelihood & BIC & AIC \\
\hline 2 & -154.7896 & 357.8834 & 333.5792 \\
\hline 3 & -149.4762 & 375.4341 & 336.9524 \\
\hline
\end{tabular}

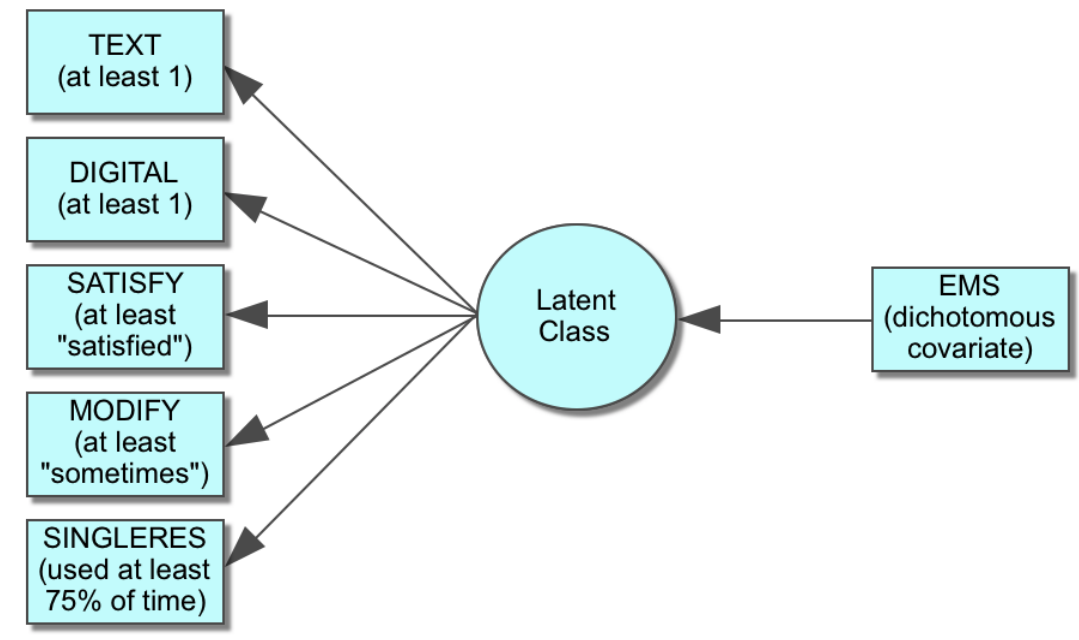

Figure 2. Latent Class Analysis with covariate model representation

close attention to the Bayesian Information Criterion (BIC), as suggested by Nylund, Asparouhov, and Muthén's (2007) Monte Carlo simulation study. Inspection of model fit statistics led us to a 2-class model, because, as can be seen in Table 2, the 2-class model had the lower BIC value. Moreover, the 3-class model resulted in one class with only 7 teachers included, making it difficult to interpret its meaning.

Analyzing differences in selection and use of curriculum between EMSs and their peers (RQ3). In regard to the third research question, we added EMS status to the LCA model as a covariate. We had hypothesized that teacher expertise might be related to the extent to which curriculum was modified (for instance, see Son \& Kim, 2015). When a covariate is added to an LCA model (see Figure 2), it is analogous to logistic regression and coefficients are interpreted as logits. By converting these into probabilities, we were able to establish how many times more/less likely EMS teachers were to be in one latent class over another.

To further explore the role of EMS status, we examined raw differences in responses to categorical items and used Welch's $t$ test to analyze differences between EMS teachers and those without the credential on the curriculum control composite score (CURRCONT). We used Welch's $t$-test because it is robust against violations of the assumption of equality of variances and Levene's test indicated that the variances between the EMS and non-EMS group on the curriculum control composite score were not equal $(F(1,54)=4.6103, p=.03629)$. However, some caution should be taken because the curriculum control composite scores for both EMS and non-EMS teachers were not normally distributed according to results from Shapiro-Wilk's test of normality (EMS: $W=$ $0.90982, p<.05$; non-EMS: $W=0.79161, p<.001$ ).

\section{FINDINGS}

Teachers' Reported Use of, and Satisfaction with, Curriculum Resources (RQ1)

Descriptive findings indicate that when the 56 teachers reported on curriculum materials they use in their classrooms, they collectively reported 135 resources categorized as either TEXT or DIGITAL, and 49 teachers reported using at least one TEXT and 35 teachers reported using at least one DIGITAL resource. Of the total number of resources categorized as TEXT or DIGITAL, 74 (55\%) were coded as TEXT and 61 (45\%) were coded as DIGITAL. Of the TEXT materials, teachers collectively reported that $62 \%$ were required by their district or school, as opposed to 34\% of DIGITAL materials. A similar disparity was found between TEXT and DIGITAL materials that were reported as neither required nor suggested ( $12 \%$ and $51 \%$, respectively). By contrast, TEXT and DIGITAL materials were similarly reported to not be frequently suggested by their district or school ( $26 \%$ and $15 \%$, respectively). Therefore, it was found to be quite common for teachers to use required TEXT materials and to locate DIGITAL materials on their own, without recommendation from their school or district. 


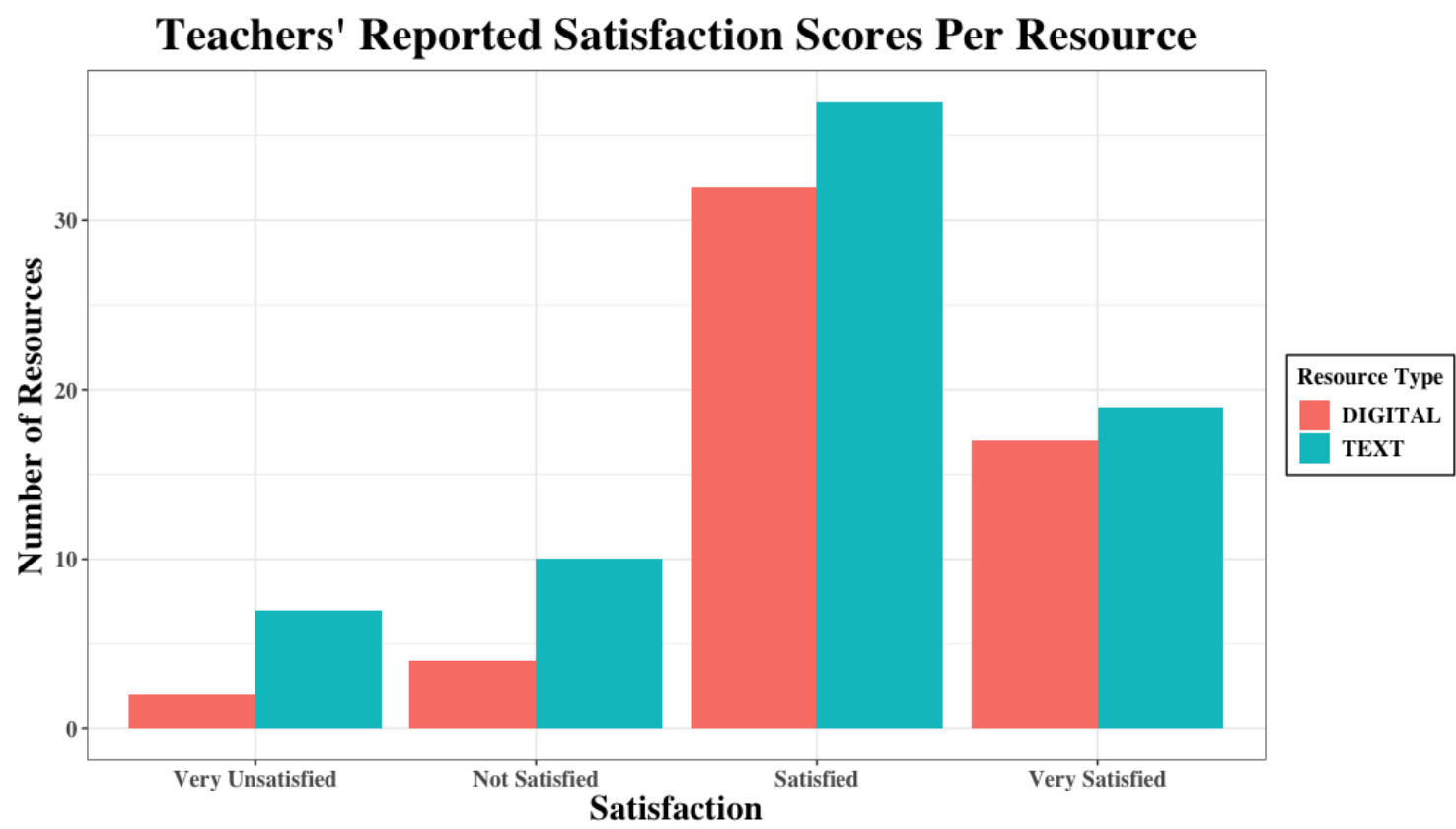

Figure 3. Bar chart of teachers' satisfaction levels of both digital and text curriculum materials

\section{Teachers' Reported Modification Scores Per Resource}

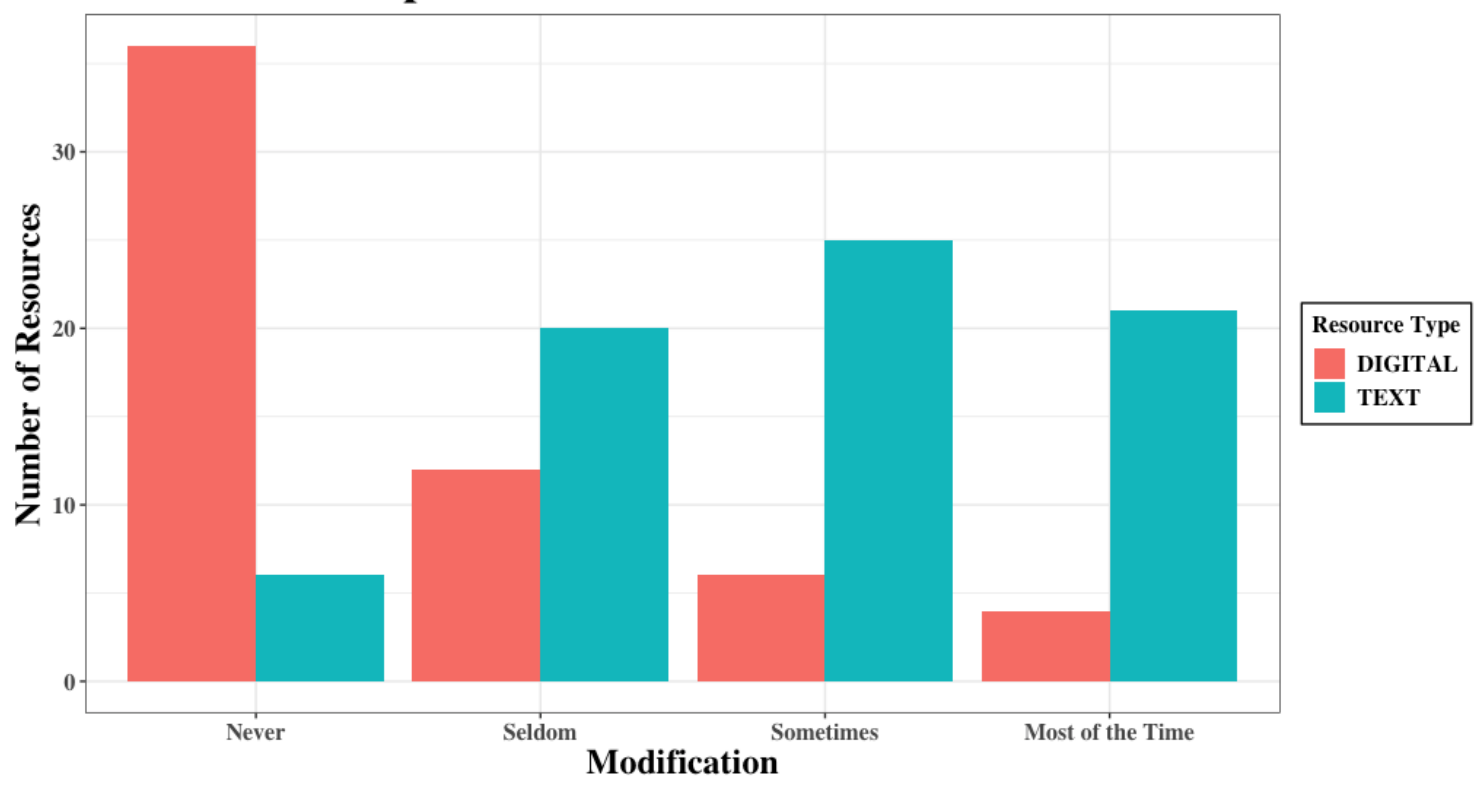

Figure 4. Bar chart of teachers' frequency of modifying digital and text curriculum materials

Despite the disparity between the proportion of TEXT and DIGITAL materials being required, teachers reported being overall satisfied with both (see Figure 3), with very few reporting being unsatisfied. Moreover, teachers reported about the same level of satisfaction with TEXT materials as DIGITAL materials. On the other hand, teachers reported vast differences in their frequency of modifying TEXT and DIGITAL materials (see Figure 4), reporting much more frequently modifying TEXT materials (just over $1 / 2$ reported modifying at least sometimes) as opposed to DIGITAL (less than $1 / 4$ reported modifying at least sometimes). This perhaps comes as no surprise because some DIGITAL materials are not easily modified, while TEXT materials are typically easier to modify. For instance, modifying a video would be difficult, while modifying a worksheet would be relatively simple.

In regard to the proportion of instructional time that students used the 135 curriculum materials that were reported, TEXT materials were observed to be used by students much more frequently than were DIGITAL materials (see Figure 5). The vast majority of DIGITAL materials were used by students less than $15 \%$ of instruction time, as can be seen in the three left-most bars in the top histogram in Figure 5. By contrast, about half of the TEXT materials were reported to be used by students for at least $50 \%$ of instructional time, as can be seen in the bottom histogram in Figure $\mathbf{5}$ which is relatively symmetric around the $50 \%$ mark on the horizontal axis. 


\section{Teachers' Reported Proportion of Time Students Use Resources}

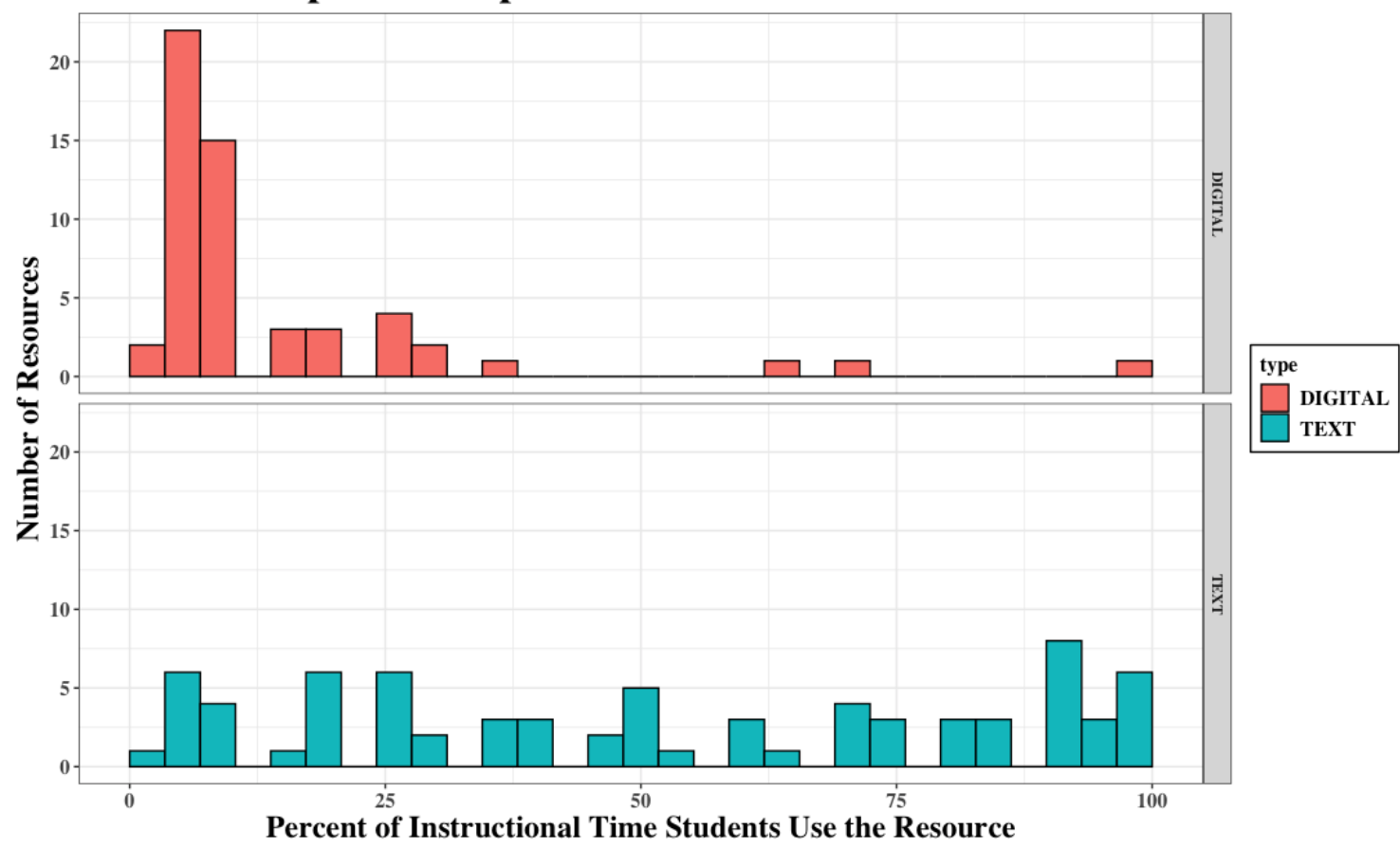

Figure 5. Histogram of teachers' report on the proportion of instructional time their students used digital and text resources

Overall, these descriptive statistics indicate that DIGITAL materials were reported slightly less frequently, were rarely required by schools or districts, were infrequently modified, and were not generally used for a significant proportion of instructional time. By contrast, TEXT materials were slightly more often reported, were more often reported as required by schools or districts, were frequently modified, and were used for a much higher proportion of instructional time. Over the next sections, we provide a more robust examination of the patterns in teachers' use of TEXT and DIGITAL curriculum materials-first by way of latent class analysis and then by examining the role of teacher expertise in observed patterns.

\section{Profiles of Blended and Non-Digital Curriculum Resource Users (RQ2)}

Results of the LCA indicated that the most salient differences in the two latent classes were 1) use of digital curriculum materials, 2) use of a single curriculum material by students for at least $75 \%$ of instruction time across the year, and 3) at least sometimes modifying curriculum materials (see Figure 6). Use of at least 1 text resource and overall satisfaction were found to have similar likelihoods of response by the two classes. Because the probabilities of using digital curriculum materials resulted in $100 \%$ for one class and $0 \%$ for the other class, for ease of referring to the two classes, we have called the classes Blended and NonDigital.

Blended curriculum material users (62.5\% of teachers) were observed to not only have $100 \%$ probability of using at least 1 digital resource, they also were unlikely to report having students use a single resource at least $75 \%$ of the time (probability = .39; see Figure 6), and even less likely to report modifying curriculum materials at least sometimes (probability =.28). Perhaps this is unsurprising since digital curriculum materials are not as easily modified as text curriculum materials, but, Blended curriculum material users were also found to be highly likely to use at least 1 text resource (probability $=.83$ ). Moreover, one-third of teachers in the Blended latent class reported using $2(29 \%)$ or $3(6 \%)$ text curricula materials-a striking similarity with the teachers in the Non-Digital latent class, of whom $38 \%$ reported using $2(24 \%)$ or $3(14 \%)$ text curricula materials. On the other hand, $49 \%$ of Blended curriculum material users reported using $2(26 \%), 3(20 \%)$, or 4 (3\%) digital curricula materials.

Upon examining the modification rates of Blended curriculum material users disaggregated by text or digital, only 4 teachers reported modifying digital materials at least sometimes (mean modification $\geq 3$ ), while 19 teachers $(54 \%)$ reported modifying text materials at least sometimes. Therefore, when examining only text materials, teachers in the Blended and Non-Digital latent classes were quite similar in their modification rates. Similarly, teachers in the Blended latent class were similarly likely to report relatively high satisfaction rates $(3=$ satisfied, $4=$ very satisfied $)$ regardless of whether the materials were digital $(M=3.234, S D=$ $0.70, M E D=3.00, I Q R=1.00)$ or text $(M=3.01, S D=0.72, M E D=3.00, I Q R=0.00)$.

To provide further detail, teachers within the Blended latent class reported a total of 62 digital curriculum resources (see Table 3). Of these 62 , there were 22 that were distinct identifications (4 of the 62 were reported too vaguely to expressly identify them, such as teachers who reported "other websites"). Of the 22 distinct resources, 6 of them accounted for more than $1 / 3$ of the resources collectively reported (24 of 62) and those 6 resources are typically used for formative assessment purposes: MobyMax ( $n$ $=11)$, IXL ( $n=5)$, Xtra Math ( $n=4)$, Khan Academy $(n=2)$, STAR Math $(n=1)$, and ALEKS $(n=1)$.

The Blended class included some within-class variations around the details of curricular practices. For example, one teacher reported using the Eureka Math textbook, and using both ALEKS and MobyMax as digital curriculum resources. This same teacher also reported that Eureka Math and ALEKS were required by her school or district but that MobyMax was a resource that she chose 


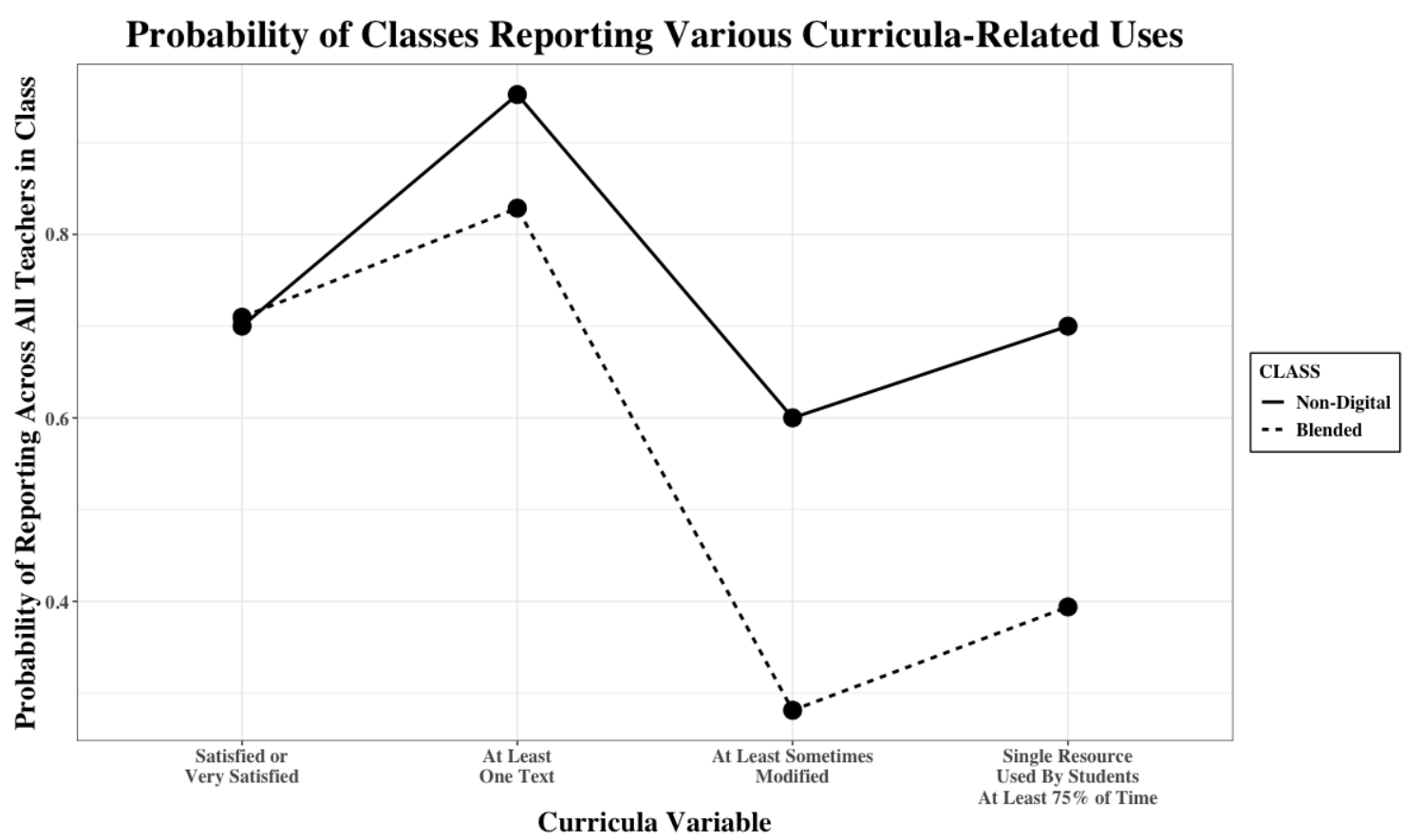

Figure 6. Profile plot of probabilities of each class per aspect of curriculum material use

Table 3. Digital sources reported by teachers in the Blended class

\begin{tabular}{|c|c|}
\hline Resource & Frequency \\
\hline Moby Max & 11 \\
\hline Reflex Math & 9 \\
\hline Greg Tang Math & 5 \\
\hline $\mathrm{IXL}$ & 5 \\
\hline XtraMath & 4 \\
\hline Other & 4 \\
\hline ST Math & 3 \\
\hline envision Pearson Realize & 2 \\
\hline Front Row & 2 \\
\hline Teachers Pay Teachers & 2 \\
\hline Ed Puzzle & 2 \\
\hline Khan Academy & 2 \\
\hline ALEKS & 1 \\
\hline BrainPop & 1 \\
\hline Go Get Waggle & 1 \\
\hline Hour of Code & 1 \\
\hline National Library of Virtual Manipulatives & 1 \\
\hline Math Is Fun & 1 \\
\hline Prdigy & 1 \\
\hline Scratch & 1 \\
\hline STAR Math & 1 \\
\hline YouTube & 1 \\
\hline
\end{tabular}

to use. Moreover, as previously theorized, this teacher reported at least sometimes modifying Eureka Math but seldom modifying ALEKS and MobyMax. Regarding satisfaction, she reported being satisfied with both Eureka Math and MobyMax but not being satisfied with ALEKS. Also, as might be expected, this teacher reported that students used Eureka Math during $85 \%$ of instructional time, ALEKS during 10\%, and MobyMax during $5 \%$.

To contrast, TEXT resources reported by teachers in the Blended and Non-Digital latent classes are listed along with frequency counts in Table 4. Comparing Blended and Non-Digital, 11 distinct materials were reported, collectively, by teachers in the Blended class and 9 by teachers in the Non-Digital class. Moreover, the most common reported text material in each class was Go Math (51.4\% of Blended teachers) and enVision (52.4\% of Non-Digital).

To exemplify some of the variation in teachers' use of TEXT curricula in the Non-Digital class, one teacher in this class reported using Everyday Mathematics as her only textbook resource. The textbook was required by the district, and the teacher reported being satisfied with the curriculum resource and sometimes modifying it. We consider this teacher's curricular decisions and instruction to be driven primarily by the district's recommendations. But another teacher reported using several text resources: enVision was the required TEXT, Fosnot's Contexts for Learning Mathematics was a suggested resource, and Investigations was a 
Table 4. Text resources reported by teachers in each latent class

\begin{tabular}{|c|c|c|}
\hline Resource & Blended & Non-Digital \\
\hline Go Math & $18(51.4 \%)$ & 0 \\
\hline envision & $3(8.6 \%)$ & $11(52.4 \%)$ \\
\hline Eureka Math/EngageNY & $7(20.0 \%)$ & $3(14.3 \%)$ \\
\hline My Math & $5(2.9 \%)$ & 0 \\
\hline Everyday Mathematics & $3(2.9 \%)$ & $4(19.0 \%)$ \\
\hline Math 4 Today & $4(2.9 \%)$ & 0 \\
\hline Math in Focus & $3(8.6 \%)$ & $3(14.3 \%)$ \\
\hline Investigations & $3(8.6 \%)$ & $2(9.5 \%)$ \\
\hline Math Expressions & $3(8.6 \%)$ & $2(9.5 \%)$ \\
\hline Catherine Fosnots Contexts for Learning Mathematics & $1(2.9 \%)$ & $3(14.3 \%)$ \\
\hline Core Standards for Math Steck-Vaughn & $2(2.9 \%)$ & 0 \\
\hline Everything's Coming Up Fractions with Cuisenaire Rods & 0 & $1(4.8 \%)$ \\
\hline Rocket Math & 0 & $1(4.8 \%)$ \\
\hline Unknown & $3(8.6 \%)$ & 0 \\
\hline Other & $3(8.6 \%)$ & $3(14.3 \%)$ \\
\hline
\end{tabular}

Note: 35 Blended teachers; 21 Non-Digital teachers

Table 5. Results of EMS Covariate on Latent Class Analysis Model

\begin{tabular}{ccccc}
\hline & Coefficient & SE & t-value & p-value \\
\hline (Intercept) & 0.57536 & 0.43762 & 1.315 & 0.204 \\
\hline EMS vs Not EMS & -0.11583 & 0.60484 & -0.192 & 0.850 \\
\hline
\end{tabular}

Table 6. Curriculum Control Composite Score Statistics

\begin{tabular}{cccccccc}
\hline & & Min & Q1 & Median & Mean & Q3 & Max \\
\hline \multirow{2}{*}{ Blended } & EMS (N=16) & 1.00 & 1.50 & 2.67 & 2.58 & 3.50 & 4.67 \\
\cline { 2 - 7 } & Not EMS (N=19) & 1.00 & 1.00 & 1.67 & 1.72 & 2.17 \\
\hline \multirow{2}{*}{ Non-Digital } & EMS (N=9) & 1.00 & 1.33 & 1.67 & 2.37 & 3.67 & 5.00 \\
\cline { 2 - 7 } & Not EMS (N=12) & 1.00 & 1.00 & 1.00 & 1.75 & 2.50 \\
\hline
\end{tabular}

resource that was neither required nor suggested. She was not satisfied with enVision, reported modifying it most of the time, and reported that students used it for only $5 \%$ of instructional time. On the other hand, she reported satisfaction with Fosnot's book and Investigations, reporting that she rarely modified them and that students used them for $20 \%$ and $75 \%$ of instructional time, respectively. This teacher seems to be exercising significant agency in making instructional decision, less bound by the district's requirements than other participants.

\section{Curriculum Resource Use by EMSs VS Their Peers (RQ3)}

Results of adding the EMS grouping variable as a covariate to the LCA indicated that EMS teachers were 1.58 times more likely (probability $\left.=e^{(-0.57736-0.11583)}=1.5833\right)$ to be in the Blended latent class than in the Non-Digital class-a non-statistically-significant, and non-practically-significant, result (see Table 5). More specifically, within the Blended class there were 16 EMS teachers (46\% of the latent class) and 19 non-EMS teachers ( $54 \%$ of the latent class), while within the Non-Digital class there were 9 EMS teachers ( $43 \%$ of the latent class) and 12 non-EMS teachers ( $57 \%$ of the latent class).

Although the EMS grouping variable did not statistically significantly explain differences between the two latent classes, we detected differences among some of the variables independently. One important difference we found was related to the curriculum control composite score-on which no differences were found overall between the Blended and Non-Digital latent classes ( $M_{\text {blended }}=2.114, S D_{\text {blended }}=1.1317, M_{\text {nondigital }}=2.016, S D_{\text {nondigital }}=1.2224$ ). From a broad perspective, the mean curriculum control composite score for EMS and non-EMS teachers was $2.507(S D=1.2842)$ and $1.731(S D=0.9246)$, respectively-a statistically significant difference $(t=2.5345, \mathrm{df}=42.341, p=0.01501,95 \% \mathrm{Cl}: 0.158,1.393)$. Despite the small sample size, the effect size was medium (Cohen's $d=0.693$ ), and the achieved power was relatively high (Power $=0.791$, G*Power version 3.1; Faul et al., 2007), indicating that the difference in reported levels of curriculum control was quite meaningful. Moreover, when disaggregating these relationships by latent class, we found that the observed differences remained (see Table 6, Figure 7 and Figure 8), with EMS teachers reporting higher levels of curriculum control than their peers (a $t$-test was not conducted for these finer grained comparisons because the sample sizes are quite small after grouping by latent class). Additionally, when examining the variable REQUIRED-which indicates whether resources teachers reported were required, suggested, or neither required nor suggested by district or school administration-EMS teachers were found to be less likely than non-EMS teachers to report being required to use any particular resource $(62 \%$ to $86 \%)$ and more likely to report using resources that were neither required nor suggested by administration ( $81 \%$ to $45 \%)$. 


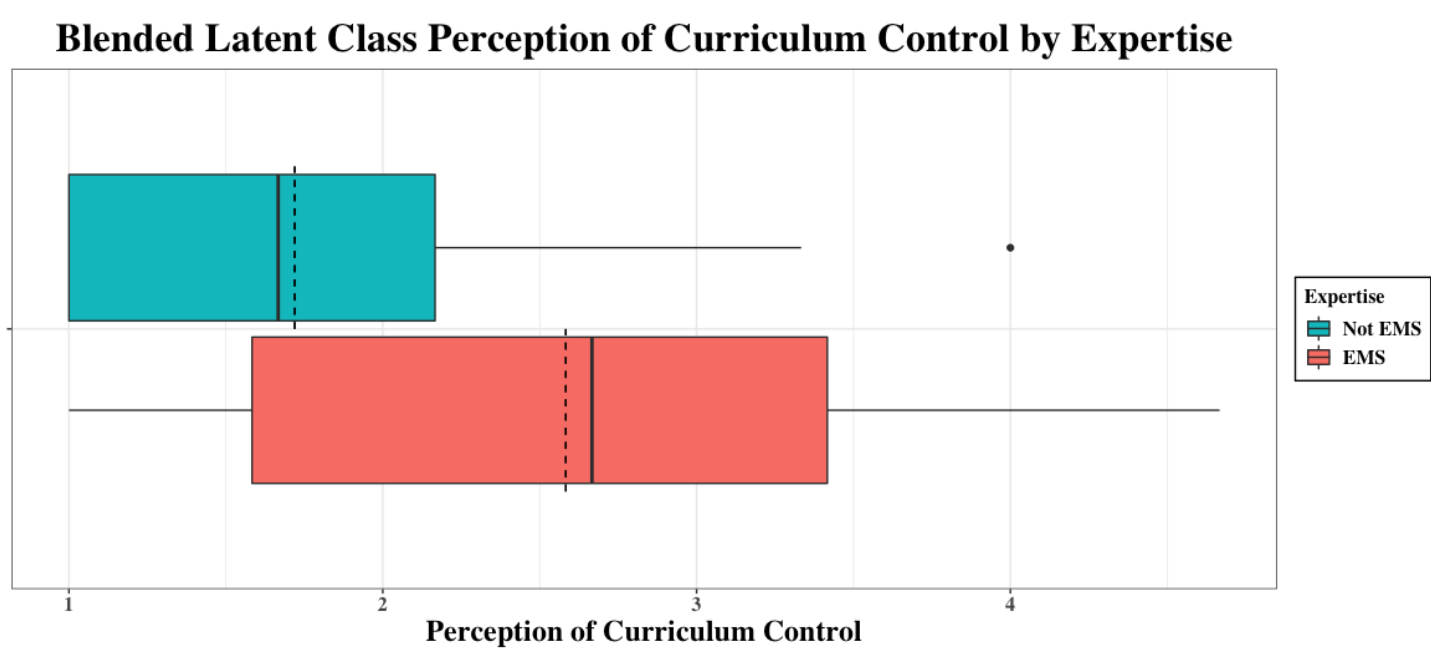

Note: Group means are indicated by dashed line

Figure 7. Curriculum control composite scores comparing EMSs to their peers within the Blended latent class

\section{Non-Digital Latent Class Perception of Curriculum Control by Expertise}

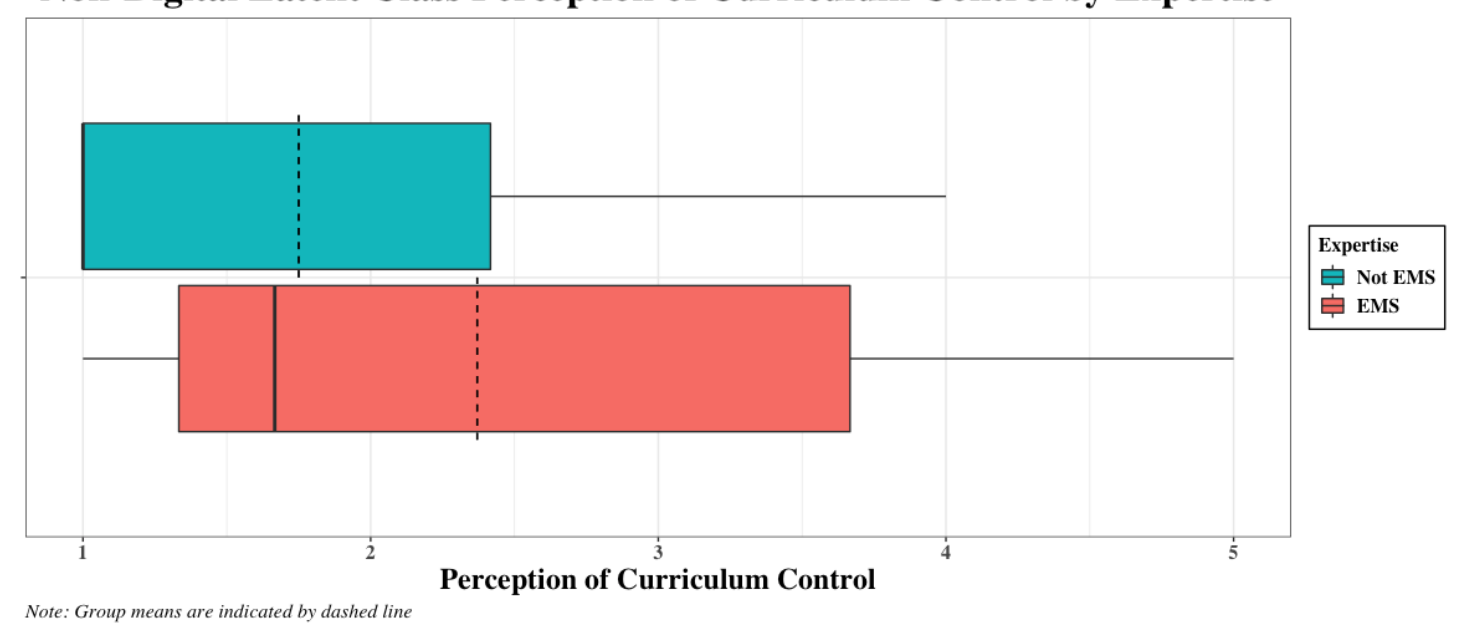

Figure 8. Curriculum control composite scores comparing EMSs to their peers within the Non-Digital latent class

\section{DISCUSSION}

This research revealed two different profile patterns in curriculum use among a group of elementary teachers. In the Blended profile, teachers used a combination of online resources and text resources. They were less likely to modify their resources-yet they modified their text resources in a similar manner to those who only reported using text resources-and were less likely to center their enacted curriculum around a specific resource. There was a wide variety of DCRs reported, but many were skill-based, like MobyMax and Reflex Math that focus on fluency or addressing "gaps" in specific mathematical skills. In the Non-Digital profile, teachers taught exclusively from text resources, and their instruction was more likely to be guided by a single published resource like the enVision textbook series, Eureka Math, or Everyday Mathematics.

A major finding from this analysis is that despite increases in the use of DCRs, non-digital textbooks appear to remain an important resource for elementary teachers of mathematics. Even among the Blended group, $77 \%$ reported using at least one textbook, which accounted for an average of $52 \%$ of instructional time. In contrast, the use of DCRs within this group accounted for an average of only $13 \%$ of instructional time. This could reflect teachers' uncertainty about how to use DCRs, despite recognizing the positive potential they hold (Hanson \& Carlson, 2005). It also may reflect the limitations of the agency of individual teachers as they draw on texts (Remillard, 2005); although the Blended group shows a shift towards using a combination of multiple resources rather than a single resource, a trend noted by others (Banilower et al., 2018; Choppin \& Borys, 2017), there was not a group of teachers that was consistently designing their own resources or compiling the bulk of their materials from disparate sources.

Another interesting finding is related to some of the specific resources that were reported. In particular, all of the teachers who used Go Math were in the Blended class; that is, they supplemented Go Math with DCRs. On the other hand, teachers using enVision and Everyday Mathematics were likely to not supplement with DCRs. This could be due to the specific features of these curricula, to district policy, or other factors. For instance, Banilower and colleagues (2018) reported that, in the US, elementary teachers 
supplement their mathematics textbook because they perceived their students as needing additional practice (95\%), they needed to further differentiate learning (94\%), they simply liked other activities more than those in the text (80\%), they needed to prepare students for standardized testing (60\%), or that their pacing guides indicated using supplemental activities (45\%). Although Banilower and colleagues did not survey teachers about whether or not the supplemental activities were digital, it provides some insight into how personal preferences, district influences (e.g., pacing guides), and state-level influences (e.g., standardized testing) may be connected to teachers' decisions about modifying their curriculum. However, this study is not able to tease apart the roles of these plausible influences in relation to specific curriculum resources.

Regarding EMSs, our analysis did not find any differences between the latent classes. However, we did find that, even when teaching in the same schools and districts, EMSs perceived having, and appeared to exercise, greater control over curricular decisions. This may be due to initiative taken by EMSs, as Webel and colleagues (2017) documented, or it may indicate a recognition of EMSs' expertise on the part of administrators. We found some suggestive evidence for both of these possibilities, as EMS teachers were less likely to report being required by the districts to use specific resources, and more likely to report using resources that were neither required nor suggested by their administrations.

These findings about how teacher expertise may have played a role in curriculum decisions has a few potential implications on practice. First, EMS teachers expressed perceiving more control over their curricular decisions but were not observed to have a higher likelihood of being in one latent class than another. This somewhat surprising result could imply a need for changes in the EMS program to include experiences around how to make decisions on the use of DCRs, since there were several who did not report using DCRs. We also want to clarify that this finding does not imply that teachers should be modifying all their resources or be using multiple resources. Fidelity to a well-designed curriculum is widely accepted as important for achieving the intended curriculum (Lloyd et. al, 2017). However, teachers who gain certification as a mathematics specialist are likely to be seen as leaders in their schools and districts, and should have increased capacity to "select, use, adapt, and determine the suitability" of mathematics curriculum resources in meaningful ways (AMTE, 2013, p. 8) that will impact student learning, as Tarr and colleagues (2013) speculated.

\section{Future Research}

Although the survey results provided an overview of teachers' decision-making about their curriculum use, we need more research about how individual teachers, especially EMSs, find, select, and use online resources. Prior research has suggested that teachers may fail to discriminate for quality or coherence when selecting online resources (Webel et al., 2015), but it is unclear what kinds of supports might improve curriculum selection practices.

In addition, research could investigate district processes for requiring versus suggesting resources. Although some districts use a pacing guide, others may distribute a vague structure with suggested resources and guidance about scope and sequence, and others may place substantial responsibility on teachers to find materials (e.g., the standards are the "curriculum"). Each of these models has implications for how teachers decide which materials to use and how. Future research could explore curricular decision making in each of these models.

Furthermore, this study was conducted to study the impact of teacher expertise for a program aligned to a particular state's endorsement criteria, and within schools that had varying influences on the intended curriculum-factors that certainly differ across and within states. Future research should examine how these different levels of influence on the intended curriculum impact teachers' decisions on the enacted curriculum.

\section{CONCLUSION}

Our analysis shows that with the increasing prevalence of online resources for teaching mathematics at the elementary level, there are new patterns of curriculum use. However, despite the fact that many teachers are incorporating DCRs into their instruction, textbooks still appear to retain a substantial influence on what is taught and how.

It is clear that navigating the array of curricular resources available and developing a coherent sequence of learning experiences is a significant challenge, as more teachers move to a reliance on a combination of different resources. While some of the work of filtering resources appears to be done by teachers at the individual level, some may be done by school leaders, perhaps including EMSs themselves. It may become more important to develop building capacity for assessing coherence and making recommendations at the school/district level, and then for translating these recommendations in ways that are comprehensible but also leave room for teachers' professional judgment.

\section{ACKNOWLEDGEMENTS}

This manuscript is based on research conducted as part of the Studying Teacher Expertise and Assignment in Mathematics (STEAM) project, supported by the National Science Foundation under DRK-12 grant \#1414438. Any opinions, findings, and conclusions or recommendations expressed herein are those of the authors and do not necessarily reflect the position, policy, or endorsement of the National Science Foundation. 


\section{REFERENCES}

Arbaugh, F., Lannin, J., Jones, D. L., \& Park-Rogers, M. (2006). Examining instructional practices in Core-Plus lessons: Implications for professional development. Journal of Mathematics Teacher Education, 9(6), 517-550. https://doi.org/10.1007/s10857-0069019-3

Association of Mathematics Teacher Educators. (2013). Standards for elementary mathematics specialists: A reference for teacher credentialing and degree programs. San Diego, CA.

Banilower, E. R., Smith, P. S., Malzahn, K. A., Plumley, C. L., Gordon, E. M., \& Hayes, M. L. (2018). Report of the 2018 NSSME +. Chapel Hill, NC: Horizon Research, Inc.

Banilower, E. R., Smith, P. S., Weiss, I. R., Malzahn, K. A., Campbell, K. M., \& Weis, A. M. (2013). Report of the 2012 national survey of science and mathematics education. Chapel Hill, NC: Horizon Research, Inc.

Campbell, P. F., \& Malkus, N. N. (2011). The impact of elementary mathematics coaches on student achievement. The Elementary School Journal, 111(3), 430-454. https://doi.org/10.1086/657654

Campbell, P. F., \& Malkus, N. N. (2014). The mathematical knowledge and beliefs of elementary mathematics specialist-coaches. ZDM, 46(2), 213-225. https://doi.org/10.1007/s11858-013-0559-6

Charalambous, C. Y., Hill, H. C., \& Mitchell, R. N. (2012). Two negatives don't always make a positive: Exploring how limitations in teacher knowledge and the curriculum contribute to instructional quality. Journal of Curriculum Studies, 44(4), 489-513. https://doi.org/10.1080/00220272.2012.716974

Choppin, J., \& Borys, Z. (2017). Trends in the design, development, and use of digital curriculum materials. ZDM, 49(5), 663-674. https://doi.org/10.1007/s11858-017-0860-x

Choppin, J., Carson, C., Borys, Z., Cerosaletti, C., \& Gillis, R. (2014). A typology for analyzing digital curricula in mathematics education. International Journal of Education in Mathematics, Science, and Technology, 2(1), 11-25. https://doi.org/10.18404/ijemst.95334

Cohen, D. K., \& Hill, H. C. (2001). Learning policy: When state education reform works. New Haven, CT: Yale University Press. https://doi.org/10.12987/yale/9780300089479.001.0001

Davis, J., Choppin, J., Roth McDuffie, A., \& Drake, C. (2013). Common Core State Standards for Mathematics: Middle School Teachers' Perceptions. Rochester, NY: Warner Center for Professional Development and Education Reform.

de Araujo, Z., Webel, C., \& Reys, B. B. (2017). Preparing elementary mathematics specialists: Essential knowledge, skills, and experiences. In M. B. McGatha \& N. R. Rigelman (Eds.), Elementary Mathematics Specialists (pp. 19-32): Association of Mathematics Teacher Educators (AMTE).

Drake, C., \& Sherin, M. G. (2009). Developing curriculum vision and trust. In J. T. Remillard, B. A. Herbel-Eisenmann, \& G. M. Lloyd (Eds.), Mathematics teachers at work: Connecting curriculum materials and classroom instruction (pp. 321-337). New York, NY: Routledge.

Drijvers, P., Tacoma, S., Besamusca, A., Doorman, M., \& Boon, P. (2013). Digital resources inviting changes in mid-adopting teachers' practices and orchestrations. ZDM, 45(7), 987-1001. https://doi.org/10.1007/s11858-013-0535-1

Dziak, J. J., Lanza, S. T., \& Tan, X. (2014). Effect size, statistical power and sample size requirements for the Bootstrap Likelihood Ratio Test in Latent Class Analysis. Structural Equation Modeling, 21(4), $534-552$. https://doi.org/10.1080/10705511.2014.919819

Faul, F., Erdfelder, E., Lang, A. G., \& Buchner, A. (2007). G*Power 3: A flexible statistical power analysis program for the social, behavioral, and biomedical sciences. Behavior Research Methods, 39(2), 175-191. https://doi.org/10.3758/BF03193146

Fennell, F. S. (2011). We need elementary mathematics specialists now, more than ever: A historical perspective and call to action. NCSM Journal of Mathematics Education Leadership, 13(2), 52-59.

Gueudet, G., \& Trouche, L. (2009). Towards new documentation systems for mathematics teachers?. Educational Studies in Mathematics, 71(3), 199-218. https://doi.org/10.1007/s10649-008-9159-8

Gutiérrez, R. (2016). Strategies for creative insubordination in mathematics teaching. Teaching for Excellence and Equity in Mathematics, 7(1), 52-60.

Hanson, K., \& Carlson, B. (2005). Effective access: Teachers' use of digital resources in STEM teaching. Education Development Center, Inc.

Heck, D. J., Chval, K. B., Weiss, I. R., \& Ziebarth, S. W. (Eds.). (2012). Approaches to studying the enacted mathematics curriculum (Vol. 10). Charlotte, NC: Information Age Publishing, Inc.

Herbst, P. (2010). Practical rationality and the justification for actions in mathematics teaching. In P. Brosnan, D. B. Erchick, \& L. Flevares (Eds.), Proceedings of the 32nd North American Chapter of the International Group for the Psychology of Mathematics Education. Columbus, $\mathrm{OH}$ : The Ohio State University.

Hill, H. C. (2010). The nature and predictors of elementary teachers' mathematical knowledge for teaching. Journal for Research in Mathematics Education, 41(5), 513-545. https://doi.org/10.5951/jresematheduc.41.5.0513 
Hill, H. C., Blunk, M. L., Charalambous, C. Y., Lewis, J. M., Phelps, G. C., Sleep, L., \& Ball, D. L. (2008). Mathematical knowledge for teaching and the mathematical quality of instruction: An exploratory study. Cognition \& Instruction, 26(4), 430-511. https://doi.org/10.1080/07370000802177235

Hill, H. C., Charalambous, C. Y., \& Kraft, M. A. (2012). When rater reliability is not enough: Teacher observation systems and a case for the generalizability study. Educational Researcher, 41(2), 56-64. https://doi.org/10.3102/0013189X12437203

Hoyles, C., Noss, R., Vahey, P., \& Roschelle, J. (2013). Cornerstone mathematics: Designing digital technology for teacher adaptation and scaling. ZDM, 45(7), 1057-1070. https://doi.org/10.1007/s11858-013-0540-4

Kasten, S. E., \& Sinclair, N. (2009). Using dynamic geometry software in the mathematics classroom: A study of teachers' choices and rationales. International Journal for Technology in Mathematics Education, 16(4), 133-143.

Linzer, D. A., \& Lewis, J. B. (2011). poLCA: An R package for polytomous variable latent class analysis. Journal of Statistical Software, 42(10), 1-29. https://doi.org/10.18637/jss.v042.i10

Lloyd, G. M., \& Wilson, M. (1998). Supporting innovation: The impact of a teacher's conceptions of functions on his implementation of a reform curriculum. Journal for Research in Mathematics Education, 29(3), 248-274. https://doi.org/10.2307/749790

Lloyd, G. M., Cai, J., \& Tarr, J. E. (2017). Issues in Curriculum Studies: Evidence-Based Insights and Future Directions. In J. Cai (Ed.), Compendium for Research in Mathematics Education (pp. 244-272). Reston, VA: National Council of Teachers of Mathematics.

Manouchehri, A. (1998). Mathematics curriculum reform and teachers: What are the dilemmas? Journal of Teacher Education, 49(4), 276-286. https://doi.org/10.1177/0022487198049004005

Manouchehri, A., \& Goodman, T. (2000). Implementing mathematics reform: The challenge within. Educational Studies in Mathematics, 42, 1-34. https://doi.org/10.1023/A:1004011522216

National Council of Teachers of Mathematics. (2000). Principles and standards for school mathematics. Reston, VA: NCTM.

National Governors Association Center for Best Practices \& Council of Chief State School Officers. (2010). Common core state standards for mathematics. Washington D.C.

Nylund, K. L., Asparouhov, T., \& Muthén, B. O. (2007). Deciding on the number of classes in latent class analysis and growth mixture modeling: A Monte Carlo simulation study. Structural Equation Modeling, 14(4), 535-569. https://doi.org/10.1080/10705510701575396

Pepin, B., Choppin, J., Ruthven, K., \& Sinclair, N. (2017). Digital curriculum resources in mathematics education: Foundations for change. ZDM, 49(5), 645-661. https://doi.org/10.1007/s11858-017-0879-Z

Remillard, J. T. (2005). Examining key concepts in research on teachers' use of mathematics curriculum. Review of Educational Research, 75(2), 211-246. https://doi.org/10.3102/00346543075002211

Remillard, J. T. (2016). Keeping an Eye on the Teacher in the Digital Curriculum Race. In M. Bates, \& Z. Usiskin, (Eds.), Digital Curricula in School Mathematics (pp. 195-204). Greenwich, CT: Information Age Publishing.

Remillard, J. T., Herbel-Eisenmann, B. A., \& Lloyd, G. M. (Eds.). (2009). Mathematics teachers at work: Connecting curriculum materials and classroom instruction. New York, NY: Routledge.

Roschelle, J., Shechtman, N., Tatar, D., Hegedus, S., Hopkins, B., Empson, S., \& Gallagher, L. P. (2010). Integration of technology, curriculum, and professional development for advancing middle school mathematics: Three large-scale studies. American Educational Research Journal, 47(4), 833-878. https://doi.org/10.3102/0002831210367426

Roth McDuffie, A., \& Mather, M. (2009). Middle school mathematics teachers' use of curricular reasoning in a collaborative professional development project. In J. T. Remillard, B. A. Herbel-Eisenmann, \& G. M. Lloyd (Eds.), Mathematics teachers at work: Connecting curriculum materials and classroom instruction (pp. 302-320). New York, NY: Routledge.

Schoen, H. L., Cebulla, K. J., Finn, K. F., \& Fi, C. (2003). Teacher variables that relate to student achievement when using a Standards-based curriculum. Journal for Research in Mathematics Education, 34(3), 228-259. https://doi.org/10.2307/30034779

Sleep, L., \& Eskelson, S. L. (2012). MKT and curriculum materials are only part of the story: Insights from a lesson on fractions. Journal of Curriculum Studies, 44(4), 537-558. https://doi.org/10.1080/00220272.2012.716977

Son, J. W., \& Kim, O. K. (2015). Teachers' selection and enactment of mathematical problems from textbooks. Mathematics Education Research Journal, 27(4), 491-518. https://doi.org/10.1007/s13394-015-0148-9

Stein, M. K., \& Kaufman, J. H. (2010). Selecting and supporting the use of mathematics curricula at scale. American Educational Research Journal, 47(3), 663-693. https://doi.org/10.3102/0002831209361210

Swars, S. L., Smith, S. Z., Smith, M. E., Carothers, J., \& Myers, K. (2018). The preparation experiences of elementary mathematics specialists: Examining influences on beliefs, content knowledge, and teaching practices. Journal of Mathematics Teacher Education, 21(2), 123-145. https://doi.org/10.1007/s10857-016-9354-y

Tarr, J. E., Grouws, D. A., Chavez, O., \& Soria, V. M. (2013). The effects of content organization and curriculum implementation on mathematics learning in secondary high school courses. Journal for Research in Mathematics Education, 44(4), 683-729. https://doi.org/10.5951/jresematheduc.44.4.0683

US Department of Education. (2016). Future ready learning, reimagining the role of technology in education: 2016 National Education Technology Plan. Washington, DC.

Usiskin, Z. (2013). Studying textbooks in an information age-A United States perspective. ZDM, 45(5), 713-723. https://doi.org/10.1007/s11858-013-0514-6 
Webel, C., Conner, K. A., Sheffel, C., Tarr, J. E., \& Austin, C. (2017). Elementary mathematics specialists in "departmentalized" teaching assignments: Affordances and constraints. Journal of Mathematical Behavior, 46, $196-214$. https://doi.org/10.1016/j.jmathb.2016.12.006

Webel, C., Krupa, E. E., \& McManus, J. (2015). Teachers' evaluations and use of web-based curriculum resources in relation to the Common Core State Standards for Mathematics. Middle Grades Research Journal, 10(2), 49.

Webel, C., Tarr, J., Austin, C., Yeo, S., Sheffel, C., Dong, N., Reys, B., \& Engledowl, C. (2018). Elementary mathematics specialists and their peers: Comparing beliefs, knowledge, and instructional practices. Paper presented at the 2018 Annual Meeting of the American Education Research Association.

Webel, C., Tarr, J., Austin, C., Yeo, S., Sheffel, C., Dong, N., Reys, B., \& Engledowl, C. (2018). Elementary mathematics specialists and their peers: Comparing beliefs, knowledge, and instructional practices [Paper presentation]. The 2018 Annual Meeting of the American Education Research Association.

Weis, A. M., \& Banilower, E. R. (2014). 2012 national survey of science and mathematics education: Public release datasets user manual. Chapel Hill, NC: Horizon Research, Inc.

Yeo, S. (2018). Investigating spatial and temporal reasoning of elementary students through gamified mathematics software. In T. E. Hodges, G. J. Roy, \& A. M. Tyminski (Eds.), Proceedings of the 40th Annual Meeting of the North American Chapter of the International Group for the Psychology of Mathematics Education (pp.1271-1274). Greenville, SC. 